\title{
Spatio-temporal changes of prolyl 4-hydroxylase in granulosa cells during ovulation in eCG-hCG-treated immature rat ovaries
}

\author{
R. Nagai, N. Tanaka, Y. Fukumatsu, H. Katabuchi and H. Okamura \\ Department of Obstetrics and Gynecology, Kumamoto University School of Medicine, Honjo 1-1-1, \\ Kumamoto 860-8556, Japan
}

\begin{abstract}
The immunolocalization of prolyl 4-hydroxylase (PHase), a key enzyme of collagen synthesis, and the effects of anti-progesterone RU486 on PHase during the ovulatory process in eCG-hCG-treated immature rat ovaries were studied to investigate the mechanisms of tissue repair in follicle walls after follicular rupture. Immunolocalization of PHase was studied using an anti-rat PHase subunit monoclonal antibody, and the amount of immunoreactive PHase was measured by enzymeimmunoassay. No obvious immunolocalization of PHase was observed in theca cells throughout the ovulatory process except just after follicular rupture. In contrast, in granulosa cells, PHase was first observed at $9 \mathrm{~h}$ after the hCG injection, and the staining intensity apparently increased from 9 to $15 \mathrm{~h}$, especially around the apex of preovulatory follicles and the orifice of ruptured follicles. Consistent with these observations, PHase concentration in granulosa cells isolated from the ovaries significantly increased by $9 \mathrm{~h}(0.45 \pm 0.03 \mathrm{pg}$ per cell), and reached a peak at $15 \mathrm{~h}$ $(0.66 \pm 0.06 \mathrm{pg}$ per cell) after the hCG injection. This peak was inhibited when $20 \mathrm{mg}$ RU486 kg ${ }^{-1}$ was administered at $8 \mathrm{~h}(0.46 \pm 0.05 \mathrm{pg}$ per cell), and the RU486-inhibited PHase concentration was recovered by the concomitant administration of $10 \mathrm{mg}$ progesterone $\mathrm{kg}^{-1}(0.65 \pm 0.02 \mathrm{pg}$ per cell). The results suggest that PHase expressed in granulosa cells may play an important role in the repair of ruptured follicle walls, via progesterone-dependent PHase production.
\end{abstract}

\section{Introduction}

The role of collagenolytic enzymes in ovulation has been well studied. Proteolytic enzymes have been shown to play an important role in the rupture of ovarian follicles using synthetic substrate dinitrophenyl peptide (DNP) and $\alpha-N$-benzoyl-DLArg- $\beta$ naphtylamide (BANA) (Shibata et al., 1989). Moreover, using RU486, a synthetic steroid blocker for progesterone activity at the receptor, ovarian progesterone has been shown to be a crucial mediator during the initial $4 \mathrm{~h}$ of the ovulatory process through its regulatory action on the proteolytic enzyme activities (Iwamasa et al., 1992; Tanaka et al., 1993). However, studies regarding collagen synthesis during ovulation have not been fully performed. Considering the homeostasis of collagen synthesis and metabolism, follicle rupture and the subsequent repair of the follicle wall could be regulated by the differential action of collagenolytic enzymes and collagen synthetic enzymes. Therefore, it is interesting to investigate collagen synthetic enzymes in the ovulatory process.

Prolyl 4-hydroxylase (PHase) is a key enzyme in collagen biosynthesis. PHase catalyses the 4-hydroxylation of proline residues in procollagen (Kivirikko and Myllyla, 1982). The enzyme is a tetramer, composed of two different subunits, $\alpha$ and $\beta$ (Berg and Prockop, 1973). The increase in sera or tissue PHase reflects the high amount of collagen synthesis in tissues.

Received 13 October 1997
In the present study, the immunolocalization of PHase in eCG-hCG-treated immature female rat ovaries was investigated to clarify the mechanisms of tissue repair in the follicle wall after follicular rupture. Moreover, the effects of RU486, and RU486 combined with exogenous progesterone, on the immunoreactive concentrations of PHase in the granulosa cells isolated from the ovaries during the ovulatory process were examined for a possible mediative action of progesterone on collagen synthesis.

\section{Materials and Methods}

\section{Ovulation induction}

Immature female Wistar rats $(50-60 \mathrm{~g}$ body weight), 21 days old, purchased from Kyudo Co. Ltd (Kumamoto) were housed under controlled conditions with illumination from 07:00 to 19:00 h, fed with CE-2 (Clea Japan Inc., Osaka). At 12:00 h on day 22 of age, the animals were injected s.c. with 10 iu eCG (Serotropin; Teikoku Hormone Mfg Co. Ltd, Tokyo). The ovulation was induced $48 \mathrm{~h}$ later by an injection s.c. of 10 iu hCG (Mochida Pharmaceutical Co. Ltd, Tokyo). The animals were killed by cervical dislocation at indicated times before or after the hCG injection. All procedures were approved by the Animal Care and Use Committee of Kumamoto University School of Medicine. 
Table 1. Immunolocalization of prolyl 4-hydroxylase in eCG-hCG-treated rat ovarian follicles

\begin{tabular}{|c|c|c|c|c|c|c|c|}
\hline \multirow[b]{2}{*}{ Follicle } & \multicolumn{7}{|c|}{ Time after the hCG injection $(h)$} \\
\hline & -48 & 0 & 6 & 9 & 12 & 15 & 24 \\
\hline \multicolumn{8}{|l|}{ Preovulatory } \\
\hline Granulosa cells (apex) & - & \pm & \pm & + & & & \\
\hline Granulosa cells (base) & - & - & - & \pm & & & \\
\hline Theca externa cells (apex) & - & - & - & \pm & & & \\
\hline Theca externa cells (base) & - & - & - & - & & & \\
\hline Theca interna cells (apex) & - & - & - & \pm & & & \\
\hline Theca interna cells (base) & - & - & - & - & & & \\
\hline \multicolumn{8}{|l|}{ Postovulatory } \\
\hline Granulosa cells (apex) & & & & & ++ & ++ & $\pm *$ \\
\hline Granulosa cells (base) & & & & & + & ++ & $\pm *$ \\
\hline Theca externa cells (apex) & & & & & + & + & \pm \\
\hline Theca externa cells (base) & & & & & - & - & - \\
\hline Theca interna cells (apex) & & & & & + & + & $\pm *$ \\
\hline Theca interna cells (base) & & & & & - & - & $-*$ \\
\hline
\end{tabular}

Immunostaining was evaluated by pathologists and the degree of staining was graded as - : negative; \pm : weak; $+:$ positive; and ++ : strong.

*Luteal cells

\section{Ovarian tissue collection}

Ovaries were immediately excised from the rats at $48 \mathrm{~h}$ before the hCG injection $(-48)$, or at $0,6,9,12,15$ or $24 \mathrm{~h}$ after the hCG injection. The ovaries were fixed in $2 \%(\mathrm{w} / \mathrm{v})$ periodate-lysine-paraformaldehyde (PLP) solution for $6 \mathrm{~h}$ at $4^{\circ} \mathrm{C}$ for immunohistochemistry. After washing in a series of PBS solutions containing 10,15 or $20 \%(\mathrm{w} / \mathrm{v})$ sucrose, the ovaries were embedded in OCT compound (Miles, Elkhart, IN) and frozen in dry ice-acetone. The ovaries were cut into $6 \mu \mathrm{m}$ thick sections on a cryostat (Sakura Finetechnical Co. Ltd, Tokyo) and dried in air.

\section{Immunohistochemistry}

A monoclonal antibody raised in mouse against rat PHase $\alpha$ subunit (Bai et al., 1986) was obtained from Fuji Chemical Industries Ltd (Toyama). The slides were treated in methanol for 30 min with $3 \%(\mathrm{v} / \mathrm{v}) \mathrm{H}_{2} \mathrm{O}_{2}$ to minimize endogenous peroxidase activities. Ovarian tissue sections were incubated overnight at $4^{\circ} \mathrm{C}$ with the primary antibody and then washed three times in PBS. Immunoperoxidase staining of PHase was performed on frozen sections by using a Labeled Streptavidin Biotin method kit (DAKO JAPAN Co., Kyoto). Peroxidase activities were visualized with 3,3'-diaminobenzidine (Sigma, St Louis, MO) as a substrate in Tris- $\mathrm{HCl}$ buffer $\left(0.5 \mathrm{mg} \mathrm{ml}^{-1}\right.$, $\mathrm{pH}$ 7.6) containing $0.01 \%(\mathrm{v} / \mathrm{v}) \mathrm{H}_{2} \mathrm{O}_{2}$. Nuclear staining was performed with $1 \%(\mathrm{v} / \mathrm{v})$ methyl green in water. Positive staining was visualized as brown reaction products. Negative controls were prepared as described above but omitting the first antibody or using nonimmune mouse serum instead of the first antibody. The staining intensity was evaluated independently by two pathologists, and classified into four grades (-: negative; \pm : weak; + : positive; and ++ : strong).
In each experiment at any time, at least five rats were examined, and 20 follicles in each ovary were evaluated.

\section{RU486 treatment}

RU486 (RU38486, Roussel-Uclaf, Romainville) was dissolved in $70 \%(\mathrm{v} / \mathrm{v})$ ethanol $\left(10 \mathrm{mg} \mathrm{ml}^{-1}\right)$, and a dose of $20 \mathrm{mg}$ RU486 $\mathrm{kg}^{-1}$ was administered s.c. to rats at $8 \mathrm{~h}$ after the hCG injection. Progesterone (10 $\mathrm{mg} \mathrm{kg}^{-1}$; Progehormon, Mochida Pharmaceutical Co., Tokyo) was given concomitantly with $20 \mathrm{mg}$ RU486 $\mathrm{kg}^{-1}$ at $8 \mathrm{~h}$ after the hCG injection to examine the reversal effects of progesterone. The doses of RU486 and progesterone used were chosen according to the results of previous experiments (Iwamasa ef al., 1992; Tanaka et al., 1993). Control rats received $0.2 \mathrm{ml} 70 \%(\mathrm{v} / \mathrm{v})$ ethanol at $8 \mathrm{~h}$ after the $\mathrm{hCG}$ injection. The oviducts were separated from the ovaries in each group at $24 \mathrm{~h}$ after the hCG injection, placed on a glass slide, and the number of oocytes was counted under a dissecting microscope to check the effect of $20 \mathrm{mg}$ RU486 $\mathrm{kg}^{-1}$ on ovulation rates.

\section{Preparation of granulosa cells}

The ovaries were placed under a stereo microscope (VMZ I; OLYMPUS Co., Tokyo), and granulosa cells were separated by puncturing the mature follicles with a 27-gauge needle. Granulosa cells were isolated from the ovaries by pressuring gently through a $77 \mu \mathrm{m}$ nylon mesh and centrifuging at $1700 \mathrm{~g}$ for $5 \mathrm{~min}$, as described by Fukumatsu et al. (1992).

\section{Prolyl 4-hydroxylase assay}

The granulosa cells were isolated from the ovaries in each group $48 \mathrm{~h}$ before $(-48)$, and $0,6,9,12,15$ and $24 \mathrm{~h}$ after the 

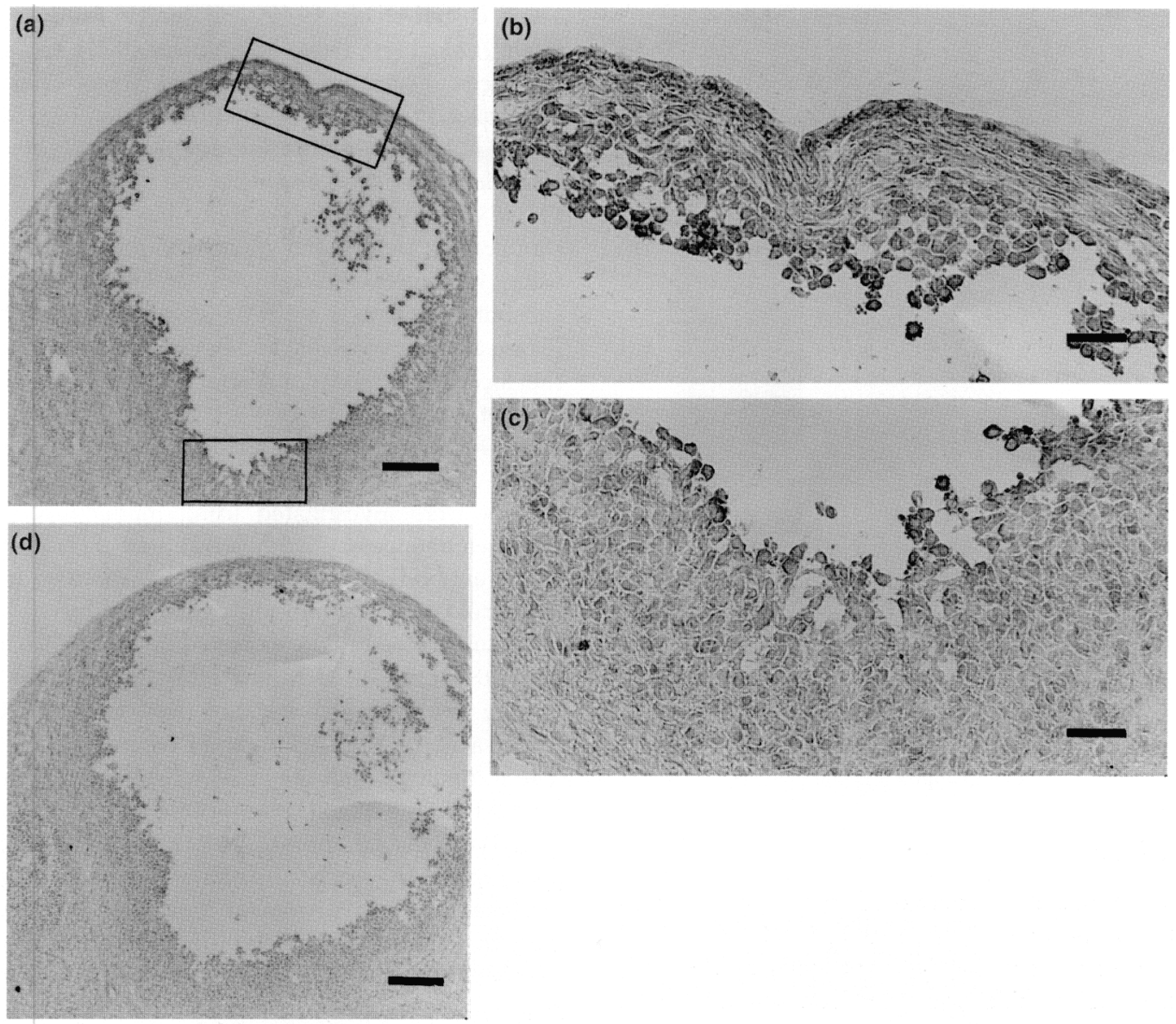

Fig. 1. (a) Immunohistochemical localization of prolyl 4-hydroxylase in immature rat ovarian follicles $15 \mathrm{~h}$ after hCG injection. Higher magnification of the apical (b) and basal (c) walls. (d) Negative control. Methyl green staining. Scale bars represent (a,d) $200 \mu \mathrm{m}$ and $(b, c) 20 \mu \mathrm{m}$.

hCG injection as described above. After the number of granulosa cells in the pellets had been counted, the cells were sonicated $\left(2 \times 10^{4} \mathrm{~s}^{-1}, 20 \mathrm{~s}\right)$ in $100 \mathrm{mmol}$ Tris- $\mathrm{HCl} \mathrm{l}^{-1}$ buffer, $\mathrm{pH} 7.0$ and centrifuged at $18000 \mathrm{~g}$ for $10 \mathrm{~min}$. The supernatants were stored at $-20^{\circ} \mathrm{C}$ until assay. The immunoreactive concentrations of PHase in $1 \mathrm{ml}$ assay samples containing at least $2 \times 10^{6}$ granulosa cells were measured using a specific rat prolyl 4-hydroxylase enzymeimmunoassay kit (Fuji Chemical Industries Ltd, Toyama). The values were expressed as pg per cell. The sensitivity of the assay was $80 \mathrm{ng} \mathrm{ml}^{-1}$, and the crossreactivity with the other substances was very low (Bai et al., 1986). The intra- and interassay coefficients of variations were $3.2 \%$ and $4.8 \%$, respectively.

\section{Statistical analysis}

All data were presented as mean \pm SEM. The significance of differences in concentration of PHase among treated and untreated groups at any given point during the ovulatory process was determined by Duncan's multiple range test after a two-way ANOVA of means of all experimental groups that could be paired across the $15 \mathrm{~h}$ period of study. In the other experimental groups, the significance of differences was determined by Duncan's multiple range test after a completely randomized one-way ANOVA of the means of the groups. The threshold of significance was set at $P=0.05$.

\section{Results}

\section{Immunolocalization of prolyl 4-hydroxylase in follicular walls}

The immunohistochemical localization of PHase in follicular walls during eCG-hCG-induced ovulation is shown (Table 1). The localization of PHase was not observed in either granulosa cells or theca cells at $48 \mathrm{~h}$ before the hCG injection, just before the eCG injection. Weak staining was detectable only in granulosa cells in the apical portion of the follicles $0-6 \mathrm{~h}$ after the hCG injection. At $9 \mathrm{~h}$ after the hCG injection, just before the follicular rupture, obvious localization of PHase was seen in granulosa cells in the apical portion of the follicles, and weak staining was detected in granulosa cells of the base and in theca cells of the apex. At 12-15 h after the hCG injection, just after the follicular rupture, the staining intensity increased, especially in granulosa cells around the apex of preovulatory follicles and the orifice of ruptured follicles (Fig. 1). At $24 \mathrm{~h}$ after the hCG, in the early luteal phase, the localization of PHase was still observed in granulosa-luteal cells of the apex. 
50

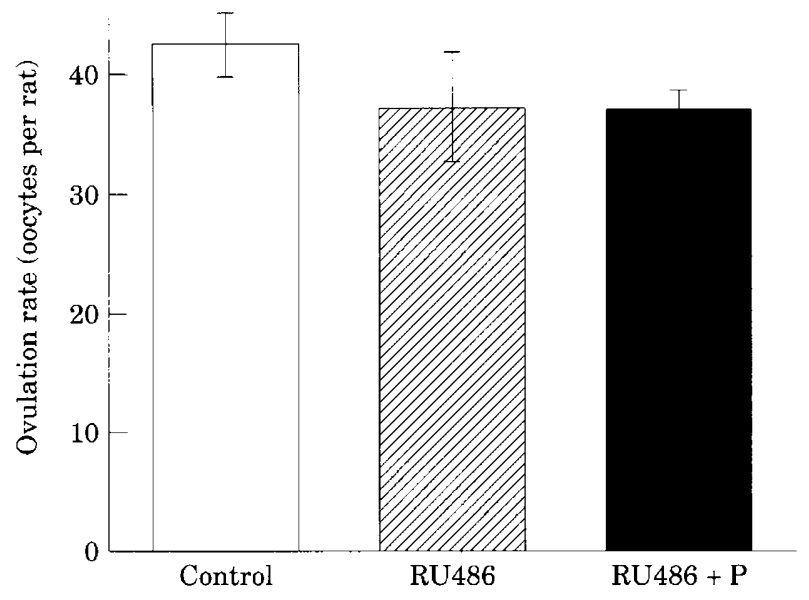

Fig. 2. Effects of RU486 and progesterone on ovulation rate in immature rats. $\square$, Control $(0.2 \mathrm{ml} 70 \%(\mathrm{v} / \mathrm{v})$ ethanol was administered s.c. $8 \mathrm{~h}$ after hCG injection); $\nabla \Delta, \mathrm{RU} 486$ (20 $\mathrm{mg}$ RU486 $\mathrm{kg}^{-1}$ was administered s.c. $8 \mathrm{~h}$ after hCG injection); and $\boldsymbol{\square}$, RU486 plus progesterone $\left(20 \mathrm{mg}\right.$ RU486 $\mathrm{kg}^{-1}$ was administered s.c. concomitantly with $10 \mathrm{mg}$ progesterone $\mathrm{kg}^{-1}$ (P) $8 \mathrm{~h}$ after hCG injection). Values are mean \pm SEM; $n=5$ per group.

\section{Effect of RU486 on ovulation rate}

There was no significant effect on the ovulation rate of $20 \mathrm{mg}$ RU486 $\mathrm{kg}^{-\mathrm{I}}$, with or without $10 \mathrm{mg}$ progesterone $\mathrm{kg}^{-1}$, when it was administered $8 \mathrm{~h}$ after the hCG injection (Fig. 2).

\section{Changes of prolyl 4-hydroxylase concentration in granulosa cells}

The immunoreactive concentration of PHase was measured by enzymeimmunoassay in granulosa cells isolated from ovaries during the ovulatory process. The PHase concentration was very low at $48 \mathrm{~h}$ before the hCG injection, increased significantly after the hCG injection $(0.30 \pm 0.03 \mathrm{pg}$ per cell at $0 \mathrm{~h}, 0.45 \pm 0.03 \mathrm{pg}$ per cell at $9 \mathrm{~h}$ ), and reached a maximum at $15 \mathrm{~h}(0.66 \pm 0.06 \mathrm{pg}$ per cell) (Fig. 3).

\section{Effect of RU486 on prolyl 4-hydroxylase concentration in granulosa cells}

When $20 \mathrm{mg}$ RU486 $\mathrm{kg}^{-1}$ was administered at $8 \mathrm{~h}$ after the hCG injection, the PHase concentration was significantly inhibited compared with controls $(0.46 \pm 0.05 \mathrm{pg}$ per cell, $P<0.01$ ) (Fig. 3). The RU486-inhibited PHase concentration in the granulosa cells at $15 \mathrm{~h}$ after hCG injection was recovered up to $0.65 \pm 0.02 \mathrm{pg}$ per cell by the concomitant administration of $10 \mathrm{mg}$ progesterone $\mathrm{kg}^{-1}$ with $20 \mathrm{mg}$ RU486 kg ${ }^{-1}$ (Fig. 3).

\section{Discussion}

Prolyl 4-hydroxylase is a key enzyme in collagen biosynthesis, and is regarded as a good indicator of collagen biosynthesis activities. PHase activity has been shown to increase in experimentally induced liver fibrosis (Takeuchi and Prockop,
1969; Risteli et al., 1976) and human chronic liver diseases (Stein et al., 1970; Fuller and Nolan, 1976). Collagen synthesis has been estimated in a tissue remodelling process by measuring PHase activity (Lerman et al., 1983; Myllyla et al., 1986), but there is little information about ovarian PHase in ovulation. The ovarian follicle and stroma of rabbits contains PHase activity, and this activity has been shown to increase significantly during the ovulatory process and luteinization, using radiometric assay with ${ }^{3} \mathrm{H}$-labelled procollagen as a substrate (Himeno et al., 1983). Monoclonal antibodies against PHase are now available and have been applied to the study of the localization and concentration of PHase in the collagen synthetic process (Bai et al., 1986). In the present study, the spatio-temporal changes of localization and concentration of PHase during ovulation in eCG-hCG-treated immature rat ovaries were investigated using immunohistochemistry and enzymeimmunoassay with an anti-rat PHase subunit monoclonal antibody. The concentration of immunoreactive PHase in granulosa cells significantly increased by $9 \mathrm{~h}$ after the hCG injection, just before the expected time of follicular rupture, and reached a peak at $15 \mathrm{~h}$, just after the follicular rupture. This change in PHase concentration was similar to the change in PHase activity reported in rabbit ovaries (Himeno et al., 1983). These findings indicate that collagen biosynthesis begins before the time of follicular rupture and becomes maximal just after the follicular rupture. However, collagenolytic enzymes are known to reach a maximum before follicular rupture (Shibata et al., 1989; Iwamasa et al., 1992). Taken together, the balance in collagen metabolism between collagenolytic and synthetic enzymes appears to be important in the physiological process of ovulation, whereas the imbalance of collagen metabolism might be concerned with the pathogenesis of certain diseases, such as luteinized unruptured follicle (Toda, 1990) and polycystic ovary (Erickson et al., 1992).

The immunolocalization of the latent form of matrix metalloproteinase-1 (proMMP-1), which is mandatory for extracellular matrix reconstruction, was previously examined during the ovulatory process in hCG-treated rabbit ovaries (Tadakuma et al., 1993). ProMMP-1 was found to be distributed in the cytoplasm of theca internal and external cells throughout ovulation. The staining intensity increased in theca interna cells and granulosa cells around the apex of follicles at $10 \mathrm{~h}$ after hCG stimulation. In the present study, PHase was first observed in granulosa cells at $9 \mathrm{~h}$ after the hCG injection, and the staining intensity increased from 9 to $15 \mathrm{~h}$, especially in granulosa cells around the apex of preovulatory follicles and the orifice of ruptured follicles. In contrast, the staining intensity in theca cells did not show significant changes during the ovulatory process, except for just after the follicular rupture. The results show that the time and localization of the collagen synthetic enzyme expression differ from those of the collagenolytic enzyme, which suggests that granulosa cells are involved not only in the dissociation of the preovulatory follicle wall but also in the repair of the ruptured follicle wall during the ovulatory process. Moreover, in the antral layer granulosa cells around the orifice of the ruptured follicles, the staining intensity of immunoreactive products of PHase apparently increased. This finding suggests that granulosa cells located in the antral layers play the most important role in the coliagen synthesis involved in the repairing process of the follicle wall after ovulation. This 


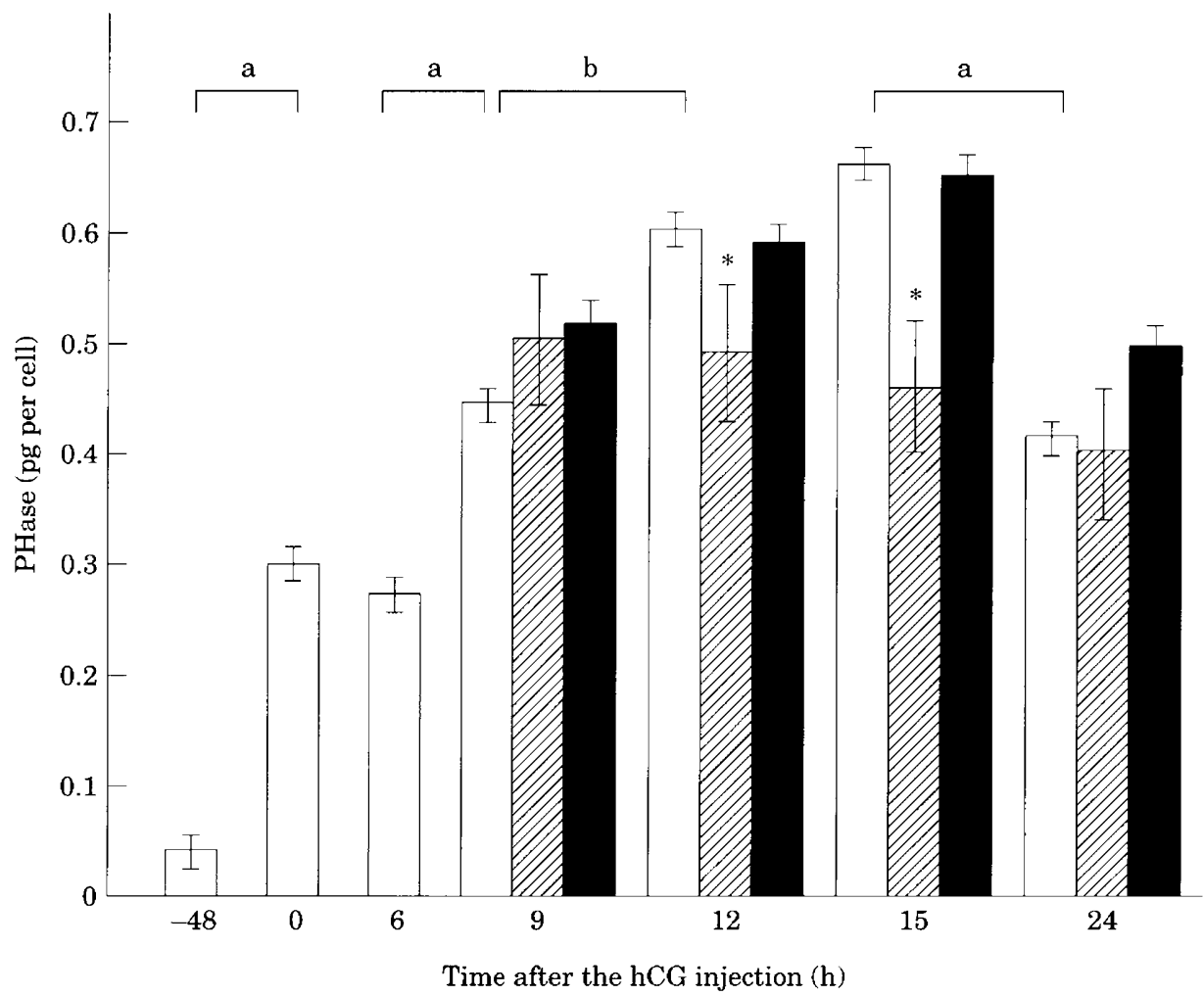

Fig. 3. Changes of prolyl 4-hydroxylase (PHase) concentration and effect of RU486 on PHase concentration in immature rat granulosa cells. $\square$, Control $(0.2 \mathrm{ml} 70 \%(\mathrm{v} / \mathrm{v})$ ethanol was administered s.c. $8 \mathrm{~h}$ after hCG injection); $\oslash$, RU486 $\left(20 \mathrm{mg}\right.$ RU486 $\mathrm{kg}^{-1}$ was administered s.c. $8 \mathrm{~h}$ after hCG injection); and $\mathbf{Q}$, RU486 plus progesterone (20 $\mathrm{mg}$ RU486 $\mathrm{kg}^{-1}$ was administered s.c. concomitantly with $10 \mathrm{mg}$ progesterone $\mathrm{kg}^{-1}$ (P) $8 \mathrm{~h}$ after hCG injection). Values are means \pm SEM; $n=6$ per group. * Significantly lower than the control $(P<0.05)$. Significantly different at different times: ${ }^{\text {a }} P<0.01$; ${ }^{\mathrm{b}} P<0.05$.

hypothesis is in agreement with the report that the interaction between integrin and extracellular matrices occurs in antral layer granulosa cells, and that this interaction may contribute to folliculogenesis (Fujiwara et al., 1996).

Ovarian steroids are known to regulate ovarian functions, such as folliculogenesis, steroidogenesis and ovulation, as local mediators. It has been shown that ovarian progesterone functions as a crucial mediator during the initial $4 \mathrm{~h}$ of the ovulatory process through its regulatory action on the proteolytic enzyme activities (Iwamasa et al., 1992), and an autocrine regulation of progesterone production through its regulatory action on ovarian 3 -hydroxysteroid dehydrogenase activity has been suggested to occur in eCG-hCG-treated immature rats (Tanaka et al., 1993). In the present study, the inhibition of endogenous progesterone action by RU486 decreased the PHase concentration in granulosa cells, and the exogenous administration of progesterone reversed this inhibition without any influence on ovulation rate, when administered at $8 \mathrm{~h}$ after the hCG injection. However, RU486 decreased the ovulation rate through the inhibition of collagenolytic enzyme activity, when administered early during the ovulatory process (Iwamasa et al., 1992). These results suggest that progesterone affects not only the collagenolytic enzyme but also the collagen synthetic enzyme. The critical time of progesterone action on PHase appears to differ from that of its action on the collagenolytic enzyme. Hence, the presence of progesterone in the initial $4 \mathrm{~h}$ of the ovulatory process may be important mainly for collagenolytic enzymerelated follicular rupture, whereas its presence just before the time of follicular rupture may be important mainly for PHaserelated repair of the ruptured follicle wall. Therefore, RU486 can inhibit follicular rupture when administered around $4 \mathrm{~h}$ after the hCG injection (Iwamasa et al., 1992), but has no influence on oocyte release when administered at $8 \mathrm{~h}$ after the hCG injection. It seems likely that ovarian progesterone functions as an indispensable local mediator in ovulation through its regulatory action on collagenolytic and collagen synthetic enzymes. Since RU486 is a inhibitor of C21 steroid receptor binding, it is possible that RU486 affected the PHase concentration, at least in part, through the inhibition of glucocorticoid receptor binding. However, data regarding the role of progesterone in ovulation and reports regarding the localization and functional activity of progesterone receptor in rat granulosa cells (Natraj et al., 1993) suggest that progesterone has a more significant role to play than RU486 in the regulation of ovarian PHase.

In conclusion, the present study indicates that granulosa cells may play a primary role in the repair of ruptured follicle walls after follicular rupture, via progesterone-dependent PHase production. 


\section{References}

Bai Y, Muragaki X, Obata K, Iwata K and Ooshima A (1986) Immunological properties of monoclonal antibodies to human and rat prolyl 4-hydroxylase Journal of Biological Chemistry 99 1563-1570

Berg RA and Prockop DJ (1973) Affinity column purification of protocollagen proline hydroxylase from chick embryos and further characterization of the enzyme Journal of Biological Chemistry 248 1175-1182

Erickson GF, Magoffin DA, Garzo VG, Cheung AP and Chang RJ (1992) Granulosa cells of polycystic ovaries: are they normal or abnormal? Human Reproduction 7 293-299

Fujiwara $\mathrm{H}$, Maeda M, Honda T, Yamada S, Ueda M, Kanzaki H, Suginami $\mathbf{H}$ and Mori T (1996) Granulosa cells express integrin alpha 6: possible involvement of integrin alpha 6 in folliculogenesis Hormone Research 46 24-30

Fukumatsu $Y$, Katabuchi $H$, Naito $M$, Takeya $M$, Takahashi $K$ and Okamura $H$ (1992) Effect of macrophages on proliferation of granulosa cells in the ovary in rats Journal of Reproduction and Fertility 96 241-249

Fuller GC and Nolan JC (1976) Prolyl hydroxylase activity in normal and diseased human liver Proceedings of the Society for Experimental Biology and Medicine 151 61-64

Himeno N, Kawamura N, Okamura H, Fukumoto M and Midorikawa $O$ (1983) Prolyl hydroxylase activity in rabbit ovary during ovulatory process Acta Obstetrica et Gynecologica Japonica 35 1777-1782

Iwamasa J, Shibata S, Tanaka N, Matsuura K and Okamura H (1992) The relationship between ovarian progesterone and proteolytic enzyme activity during ovulation in the gonadotropin-treated immature rat Biology of Reproduction 46 309-313

Kivirikko KI and Myllyla R (1982) Post-translational enzymes in the biosynthesis of collagen: intracellular enzymes Methods in Enzymology 82 245-304
Lerman RH, Apstein CS, Kagan HM, Osmers EL, Chichester CO, Vogel WM, Connelly CM and Steffee WP (1983) Myocardial healing and repair after experimental infarction in the rabbit Circulation Research 53 378-388

Myllya R, Salminen A, Peltonen L, Takala TE and Vihko V (1986) Collagen metabolism of mouse skeletal muscle during the repair of exercise injuries Pflugers Archiv European Journal of Physiology 407 64-70

- Natraj U and Richards JS (1993) Hormonal regulation, localization, and functional activity of the progesterone receptor in granulosa cells of rat preovulatory follicles Endocrinology 133 761-769

Risteli J, Tuderman L and Kivirikko KI (1976) Intracellular enzymes of collagen biosynthesis in rat liver as a function of age and in hepatic injury induced by dimethylnitrosamine. Purification of rat prolyl hydroxylase and comparison of changes in prolyl hydroxylase activity with changes in immunoreactive prolyl hydroxylase Biochenical Journal 158 369-376

Shibata S, lkuta Y, Furuki Y, Matsuura K and Okamura H (1989) BANA hydrolase and DNP peptidase activities in the ovulatory process of PMS-hCG treated immature rat Acta Obstetrica et Gynecologica Japonica 41 $1750-1754$

Stein HD, Keiser HR and Sjoerdsma A (1970) Proline-hydroxylase activity in human blood Lancet 1 106-109

Tadakuma H, Okamura H, Kitaoka M, lyama K and Usuku G (1993) Association of immunolocalization of matrix metalloproteinase $\mathrm{I}$ with ovulation in hCG-treated rabbit ovary Journal of Reproduction and Fertility 98 503-508

Takeuchi T and Prockop DJ (1969) Protocollagen proline hydroxylase in normal liver and in hepatic fibrosis Gastroenterology 56 744-750

Tanaka N, Iwamasa J, Matsuura K and Okamura H (1993) Effects of progesterone and anti-progesterone RU486 on ovarian 3-hydroxysteroid dehydrogenase activity during ovulation in the gonadotrophin-primed immature rat Journal of Reproduction and Fertility 97 167-172

Toda T (1990) Ultrasonographical study on luteinized unruptured follicle Acta Obstetrica et Gynecologica Japonica 42 1195-1202 